OPEN ACCESS

Edited by:

Matthew Zabel,

University of California at San Diego,

United States

Reviewed by:

Bernadette McGuinness,

Queen's University Belfast,

United Kingdom

Michael Hornberger,

University of East Anglia,

United Kingdom

*Correspondence:

Ming-Chyi Pai

pair@mail.ncku.edu.tw

Received: 12 July 2020 Accepted: 10 November 2020 Published: 09 December 2020

Citation:

Pai M-C and Jan S-S (2020) Have I Been Here? Sense of Location in People With Alzheimer's Disease. Front. Aging Neurosci. 12:582525. doi: 10.3389/fnagi.2020.582525

\section{Have I Been Here? Sense of Location in People With Alzheimer's Disease}

\author{
Ming-Chyi Pai ${ }^{1,2,3 *}$ and Shau-Shiun Jan ${ }^{2,4}$ \\ ${ }^{1}$ Division of Behavioral Neurology, Department of Neurology, College of Medicine, National Cheng Kung University Hospital, \\ National Cheng Kung University, Tainan, Taiwan, ${ }^{2}$ Alzheimer's Disease Research Center, National Cheng Kung University \\ Hospital, Tainan, Taiwan, ${ }^{3}$ Institute of Gerontology, College of Medicine, National Cheng Kung University, Tainan, Taiwan, \\ ${ }^{4}$ Department of Aeronautics and Astronautics, National Cheng Kung University, Tainan, Taiwan
}

Background: When navigating in a particular space, a sense of being at a current location is of great help for the navigators in reaching their destination or getting back to the start. To accomplish this work, interwoven neural structures and neurons are called into play. This system is called the heading direction cell-place cell-grid cell circuit. Evidence from various neuroscience studies has revealed that the regions responsible for this circuit are damaged in the early stages of Alzheimer's disease (AD). This may explain why wayfinding difficulty is one of the most frequent symptoms in persons with AD. The aim of this study was to examine the sense of location (SoL) in persons with mild $A D$, persons with prodromal $A D$ (prAD), and those who were cognitively unimpaired (CU).

Methods: We invited people with mild AD, prAD, and CU to participate in this study. The venue of the core experiment to assess SoL was a 660-m path located on the university campus. The participants were instructed to take a walk on the path and press a device to indicate their arrival at each of the five carefully chosen targets. The linear deviations from the target site were compared among the groups.

Results: A total of 20 AD, 28 prAD, and $29 \mathrm{CU}$ persons completed the study. Their Mini-Mental State Examination scores were on average 20 (SD 3), 24 (SD 3), and 28 (SD 2). The groups were well differentiated regarding several measurements for cognitive ability and spatial navigation. As for the SoL, the hit rates of exact location with linear deviation of $16 \mathrm{~m}$ or less were $0.05,0.54$, and 0.86 for AD, prAD, and CU persons, respectively. The hit rates were well correlated with the presence of getting lost. Also, SoL differentiated well among CU, PrAD, and AD in terms of average linear deviation.

Conclusions: Our employing linear deviation by utilizing a grid-cell function device as an assessment for SoL showed distinct features among the three groups. This model can be used to develop more delicate devices or instruments to detect, monitor, and aid spatial navigation in persons with prAD and AD.

Keywords: dementia, Alzheimer's disease, spatial navigation, humans, sense of location 


\section{BACKGROUND}

When moving in a physical space, a person may intermittently check the current location to assure being on the right path. This is called sense of location (SoL) (Jeffery, 2007). SoL helps an individual to reach his or her destination and return to the start point. To accomplish this seemingly simple work, interwoven neural structures are called into play.

It is known that a network in the brain provides navigators with knowledge of their current location and a representation of environmental scenes. This global positioning system (GPS)-like built-in neural network is called the place cell-heading direction cell-grid cell (PHG) system (Golob et al., 2001; Parron and Save, 2004; Hafting et al., 2005). The neural structures composing this system overlap with the regions which are damaged in the initial stage of Alzheimer's disease (AD) (Braak and Del Tredici, 2015), including the entorhinal cortex and its connected regions. This may explain why navigation impairment and getting lost (GL) are two of the incipient symptoms in persons with AD (Pai and Hsiao, 2002; Pai and Jacobs, 2004).

SoL, together with attention (Baddeley, 1986), landmark recognition (Lee and Pai, 2012), egocentric route following (Vogeley and Flink, 2003), forming and using cognitive maps (Jheng and Pai, 2009), translations between different spatial representations (Vann et al., 2009; Pai and Yang, 2013), and decision making (Janzen and van Turennout, 2004), plays a critical role in our daily navigation. Over the past decades, studies focusing on human navigation abilities have been carried out on participants, including cognitively unimpaired (CU) individuals, people living with $\mathrm{AD}$, or people with mild cognitive impairment (MCI) (Hort et al., 2007; Gazova et al., 2012; Lithfous et al., 2013; Lester et al., 2017; Coughlan et al., 2018; Zanco et al., 2018). The mechanisms for spatial navigation impairment (SNI) in early AD, however, are not well understood.
Given that SNI is such an important issue in dementia care, learning more about the mechanism is helpful for creating techniques to prevent GL events (Pai and Lee, 2016). The aim of this study was to examine SoL in persons living with earlyclinical-stage AD.

\section{METHODS}

\section{Participants}

We invited people with mild $\mathrm{AD}$ and those with prodromal $\mathrm{AD}$ (prAD) from a dementia special clinic and the $\mathrm{CU}$ people from the community at large to join this study. A diagnosis of $\mathrm{AD}$ was made according to the criteria developed by the National Institute on Aging-Alzheimer's Association workgroups on diagnostic guidelines for AD (McKhann et al., 2011). For the AD group, only those with a Clinical Dementia Rating (CDR) Scale score of 1.0 were included. The clinical criteria for the participants with prAD were as follows: (1) subjective memory complaints confirmed by family members, (2) Mini-Mental State Examination scores between 24 and 30 or equivalently adjusted for educational level, (3) objective memory impairment for age, (4) a CDR of 0.5, (5) largely intact functional activities of daily living, and (6) absence of dementia (Petersen et al., 1999; Busse et al., 2003; Petersen, 2004; Winblad et al., 2004; Suk and Shen, 2014). A diagnosis of $\mathrm{AD}$ or prAD was supported by medial temporal atrophy and/or posterior cortical atrophy via brain MRI and perfusion deficit in either the precuneus and/or the posterior parietal lobes and/or the posterior cingulate gyrus via brain SPECT (Scheltens et al., 1992; Matsuda, 2007; Ramusino et al., 2019). The CU group were those with normal mental states and who lived completely independently. These were mostly family members, especially spouses of patients.

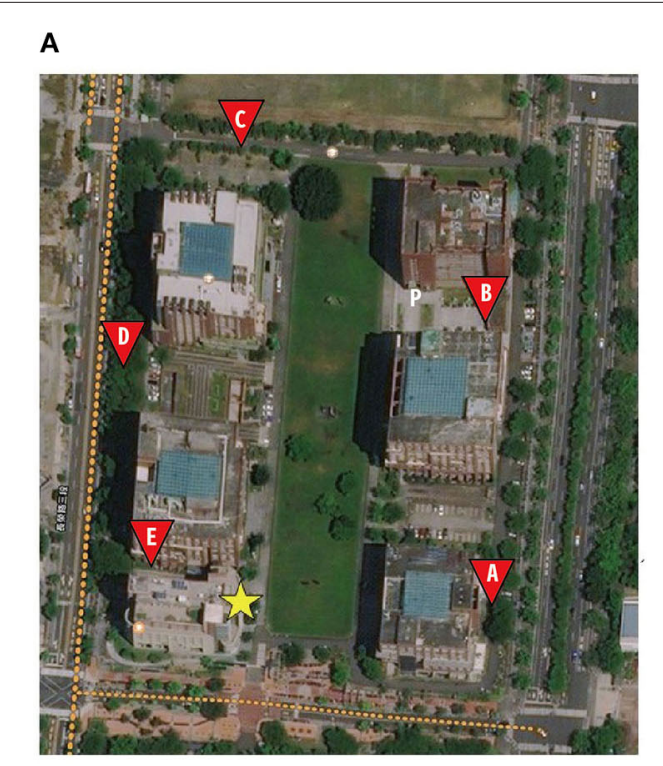

B

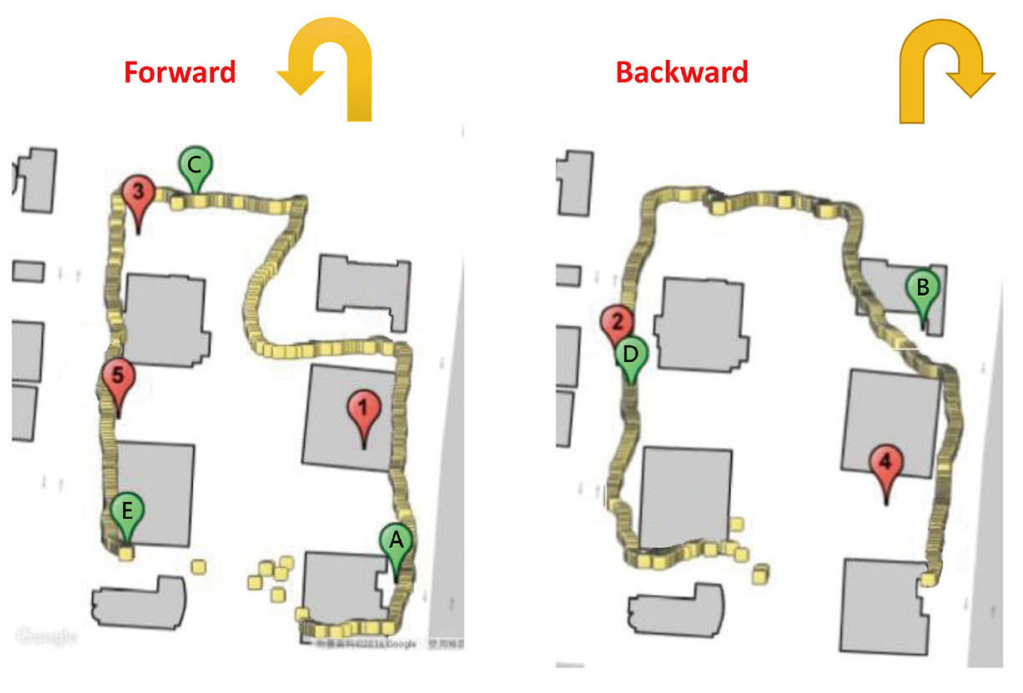

FIGURE 1 | (A) The aerial photo of the campus. (B) The path, target site locations (marked with letters A-E), the participant trace recorded by Pai-Jan device, and the areas that the participant reached (marked with numbers 1-5). The yellow star indicates the starting point of the path. Letter P indicates the participant. 


\section{Basic Neuropsychological Tests}

We administered the Cognitive Abilities Screening Instrument (CASI) (Teng et al., 1994) and the Neuropsychological Batteries developed by the Consortium to Establish a Registration of Alzheimer's Disease (CERAD) (Morris et al., 1989) to examine general and specific cognitive functions. The Questionnaire on Everyday Navigational Ability (QuENA) (Pai et al., 2012) was used to assess the participants' navigational abilities and behavior. Moreover, all participants were assessed for their abilities of perception of time and distance (Bindra and Waksberg, 1956; Grondin, 2010; Bian and Anderson, 2013), in which both perceptions were measured with respect to verbal estimation and production.

\section{Core Experiments}

The core experiment was carried out on Tzu-Chiang Campus at National Cheng Kung University. Each participant was shown a map illustrating the layout of the campus throughout the study, in which several rectangle turns are on the path for the participants to walk. The length of the path was $660 \mathrm{~m}$, on which five sites (A-E) were carefully chosen to prevent individuals from seeing the starting point. The participants, prior to the experiment, were instructed to approach the five target sites one after another and touch the screen of a tablet personal computer (PC) with an innovatively designed Pai-Jan (PJ) device (Pai et al., 2016) upon judging that they had reached the target. Figure 1A provides an aerial photo of the campus and the PJ device interface on which the designed path and the location of the target sites were shown. The location of the participant could also be seen on the PJ device interface.

Accompanied by researchers, the participants took a forward (with targets $\mathrm{A}, \mathrm{C}$, and $\mathrm{E}$ ) and a reverse route (with targets $B$ and D). The sequence of forward and reverse routes was counterbalanced among the participants to eliminate the effect produced by the two directions. The PJ device recorded the geographical location of the point by GPS when a participant touched the screen. The linear deviation of the participant from the target at each site could be precisely calculated and was treated as a variable to be compared among the three groups. Figure 1B provides the trace of a participant as recorded on the PJ device. Moreover, at each target, the PJ device also showed an arrow for the participants to point in the direction of the origin. The angular deviation from the correct direction was compared as a function of path integration (Allan, 1979; Howett et al., 2019). The design of the core experiment was akin to a daily activity when one goes outside to reach a destination held in mind, and it was an ecologically valid setting to reveal real-world evidence.

\section{Institutional Review Board}

All procedures were approved by the National Cheng Kung University Hospital Institutional Review Board for the Protection of Human Subjects. All the participants provided informed consent before participating in this study.

\section{Data Analyses}

Descriptive statistics were presented as means \pm standard deviation. SPSS (version 22.0) for Windows was used for
TABLE 1 | Demographic and neuropsychological tests.

\begin{tabular}{|c|c|c|c|c|c|}
\hline & $\begin{array}{c}\mathrm{CU} \\
(n=29)\end{array}$ & $\begin{array}{c}\text { PrAD } \\
(n=28)\end{array}$ & $\begin{array}{c}\text { AD } \\
(n=20)\end{array}$ & $p$-value & Post hoc \\
\hline Gender (M:F) & $14: 15$ & 19:9 & $7: 13$ & 0.071 & \\
\hline Age $(\text { years })^{h}$ & $69.5(6.7)$ & $71.0(7.7)$ & $73.5(8.4)$ & 0.192 & \\
\hline Education (years) $^{i}$ & $11.9(3.7)$ & $10.4(3.8)$ & $8.8(3.3)$ & $0.019^{\star}$ & $a^{\star \star}$ \\
\hline MMSE' & $27.5(2.2)$ & $24.1(3.4)$ & $20.2(2.9)$ & $0.000^{\star \star \star}$ & $\begin{array}{l}a^{\star \star \star}, b^{\star \star \star} \\
c^{\star \star \star}\end{array}$ \\
\hline $\mathrm{CDR}(\mathrm{SoB})^{i}$ & NA & $1.2(0.7)$ & $4.1(1.2)$ & $0.000^{\star \star *}$ & $e^{\star \star \star}$ \\
\hline Age at onset (y ears) ${ }^{h}$ & NA & $65.8(9.7)$ & $68.7(6.6)$ & 0.288 & \\
\hline \multicolumn{6}{|l|}{ CASIj } \\
\hline Remote memory & $10.0(0.2)$ & $10.0(0.0)$ & $9.9(0.5)$ & 0.250 & \\
\hline Recent memory & $10.6(1.1)$ & $7.0(3.2)$ & $3.3(2.7)$ & $0.000^{\star \star \star}$ & $\begin{array}{l}a^{\star \star \star}, b^{\star \star \star} \\
c^{\star \star \star}\end{array}$ \\
\hline Attention & $7.5(0.7)$ & $7.0(1.3)$ & $7.1(0.9)$ & 0.379 & \\
\hline Mental manipulation & $9.0(1.3)$ & $7.9(2.5)$ & $7.8(2.5)$ & 0.332 & \\
\hline Orientation & $17.8(0.6)$ & $16.9(1.1)$ & $10.8(4.1)$ & $0.000^{\star \star \star}$ & $a^{\star \star \star}, b^{\star \star \star}$ \\
\hline Abstract thinking & $9.6(1.7)$ & $7.5(1.6)$ & $7.5(1.5)$ & $0.000^{\star \star \star}$ & $a^{\star \star}, c^{\star \star \star}$ \\
\hline Language & $9.7(0.7)$ & $9.4(1.0)$ & $9.3(0.9)$ & 0.567 & \\
\hline Drawing & $9.9(0.3)$ & $8.9(2.2)$ & $9.3(1.1)$ & 0.063 & \\
\hline Animal & $9.0(1.9)$ & $7.6(2.4)$ & $6.4(2.4)$ & $0.009^{\star \star}$ & $a^{\star \star}$ \\
\hline CASI total score & $92.6(5.8)$ & $82.2(9.8)$ & $71.1(6.9)$ & $0.000^{\star \star \star}$ & $\begin{array}{l}a^{\star \star \star}, b^{\star \star \star}, \\
c^{\star \star \star}\end{array}$ \\
\hline
\end{tabular}

\section{CERAD}

Verbal fluency $\quad 14.9(3.5) \quad 12.5(3.7) \quad 10.7(2.2) \quad 0.000^{\star \star *} \quad a^{* \star}, c^{*}$

Boston naming test $14.7(1.0) \quad 14.2(1.0) \quad 13.7(1.5) \quad 0.045^{*} \quad a^{*}$

Word list memory $\quad 21.7(3.3) \quad 17.1(3.7) \quad 13.9(2.4) \quad 0.000^{\star \star \star} \quad a^{\star \star \star}, b^{*}, c^{\star \star \star}$

Constructional praxis $10.4(0.9) \quad 10.0(1.2) \quad 10.4(1.5) \quad 0.211$

Word list recall $\quad 7.7(1.6) \quad 4.5(2.0) \quad 1.8(1.8) \quad 0.000^{\star \star \star} \quad a^{\star \star \star}, b^{\star \star \star}$,

Word list recognition $18.8(1.7) \quad 16.8(2.3) \quad 12.9(2.4) \quad 0.000^{\star \star \star} \quad a^{\star \star \star}, b^{\star \star *}, c^{\star \star}$ Recall constructional $\quad 8.9(2.3) \quad 5.1(3.8) \quad 1.7(2.5) \quad 0.000^{\star \star \star} \quad a^{\star \star \star}, b^{\star \star}, c^{\star \star \star}$ praxis

Trail making test (TMT) ${ }^{\mathrm{g}}$

TMTa $(N ; 0 / 1 \sim 5 />5) \quad 29 ; 26 / 2 / 1 \quad 28 ; 22 / 4 / 2 \quad 19 ; 13 / 5 / 1 \quad 0.402$

TMTb (N; 0/1 5/>5) 29; 14/11/4 27; 8/11/8 $18 ; 1 / 6 / 11 \quad 0.003^{\star \star} \quad a^{\star \star}$

TMTc (N; 0/1 5/>5) 29; 27/2/0 28; 24/3/1 $19 ; 11 / 6 / 2 \quad 0.034^{*} \quad a^{\star *}$

QuENA ${ }^{j}$

Landmark and scene $\quad 1.2(1.4) \quad 2.8(1.6) \quad 3.2(1.8) \quad 0.000^{\star \star \star} \quad \mathrm{d}^{\star \star \star}, \mathrm{f}^{\star \star}$ agnosia

Egocentric agnosia $\quad 0.7(0.9) \quad 1.9(1.0) \quad 2.5(1.1) \quad 0.000^{\star \star \star} \quad d^{\star \star \star}, f^{\star \star \star \star}$

Inattention $\quad 1.1(0.8) \quad 2.1(1.4) \quad 2.3(1.8) \quad 0.007^{\star \star} \quad d^{\star}, f^{\star}$

Heading $\quad 0.9(1.0) \quad 2.1(1.7) \quad 2.4(1.5) \quad 0.001^{\star \star *} \quad d^{\star \star}, f^{\star \star}$

disorientation

QuENA total score $\quad 4.0(3.3) \quad 8.5(5.0) \quad 10.3(4.3) \quad 0.000^{\star \star \star} \quad \mathrm{d}^{\star \star *}, f^{\star \star \star \star}$ Getting lost, N (\%) $\quad$ NA $\quad 9(32.1 \%) \quad 10(50.0 \%) \quad 0.260$

Magnetic resonance imaging ${ }^{h}$

MTA visual rating NA 27; $1.7(1.0) 19 ; 2.6(1.3) 0.019^{\star} \quad e^{\star}$

scale $[N ; \mathrm{M}(\mathrm{SD})]$

PA visual rating scale NA $27 ; 1.2(0.8) 19 ; 1.5(1.0) 0.444$

$[N ; \mathrm{M}(\mathrm{SD})]$

Data are presented as mean (standard deviation).

$C U$, cognitively unimpaired; PrAD, prodromal $A D ; A D$, Alzheimer's disease; a, $C U>A D$; b. PrAD > AD; $c, C U>\operatorname{Pr} A D ; d, C U<A D ; e, \operatorname{Pr} A D<A D ; f, C U<\operatorname{PrAD} ; g$, chi-square test $p$-value; $h$, ANOVA p-value; $i$, Kruskal-Wallis test for comparison among groups and Dunn's test for post hoc; j, ANCOVA; MMSE, Mini-mental State Examination; CDR SoB, Clinical Dementia Rating Sum of Box; CASI, Cognitive Abilities Screening Instrument; CERAD, Consortium to Establish a Registry for Alzheimer's Disease, post hoc analysis by Scheffe Test; QuENA, Questionnaire on Everyday Navigational; MTA, medial temporal lobe atrophy; PA, posterior atrophy; in visual rating scale: $M$, mean; $S D$, standard deviation. ${ }^{\star} p \leq 0.05,{ }^{\star \star} p \leq 0.01,{ }^{\star \star *} p \leq 0.001$. 
TABLE 2 | Time perception and self-motion deviation.

\begin{tabular}{|c|c|c|c|c|c|c|c|c|}
\hline & $\mathrm{CU}(n=25)$ & $\mathrm{CU}(n=26)$ & $\operatorname{PrAD}(n=25)$ & $\operatorname{PrAD}(n=28)$ & $\mathrm{AD}(n=18)$ & $\mathrm{AD}(n=15)$ & $p$-value & Post hoc \\
\hline \multicolumn{9}{|c|}{ Verbal time estimation deviation (second) } \\
\hline 10 & $3.7(4.1)$ & & $4.1(3.7)$ & & $4.7(3.6)$ & & 0.707 & \\
\hline 30 & $6.0(7.2)$ & & $9.2(7.1)$ & & $12.7(9.7)$ & & $0.029^{\star}$ & A \\
\hline 60 & $12.1(12.8)$ & & $17.6(15.7)$ & & $24.8(14.9)$ & & $0.022^{\star}$ & A \\
\hline \multicolumn{9}{|c|}{ Time production deviation (second) } \\
\hline 60 & $11.0(10.3)$ & & $17.5(11.2)$ & & $22.1(10.5)$ & & $0.005^{\star \star}$ & A \\
\hline \multicolumn{9}{|c|}{ Verbal distance estimation deviation (meter) } \\
\hline 10 & & $2.4(1.9)$ & & $2.4(2.0)$ & & $3.3(2.7)$ & 0.361 & \\
\hline 50 & & $12.1(8.8)$ & & $14.2(10.9)$ & & $18.1(9.1)$ & 0.171 & \\
\hline 100 & & $30.6(21.7)$ & & $29.9(28.9)$ & & $42.1(30.4)$ & 0.321 & \\
\hline 100 & $34.9(28.2)$ & & & $22.8(16.9)$ & & $42.8(19.3)$ & $0.017^{\star}$ & B \\
\hline
\end{tabular}

Data are presented as mean (standard deviation). Post hoc analysis by Dunn's test.

$C U$, cognitively unimpaired; PrAD, prodromal $A D ; A D$, Alzheimer's disease; $a, C U<A D$; $b$, PrAD $<A D ; c, C U<\operatorname{Pr} A D$.

${ }^{*} p \leq 0.05,{ }^{* *} p \leq 0.01$; outliers (>2.5 standard deviation) are excluded.

TABLE 3 | Sense of location.

\begin{tabular}{|c|c|c|c|c|c|}
\hline & $\mathrm{CU}(n=29)$ & $\operatorname{PrAD}(n=28)$ & $\mathrm{AD}(n=20)$ & $p$-value & Post hoc \\
\hline \multicolumn{6}{|c|}{ Linear deviation (meter) } \\
\hline P1 & $19.5(32.3)$ & $39.0(46.2)$ & $90.5(62.0)$ & $0.000^{\star \star \star}$ & $a^{\star \star \star}, b^{\star \star \star}$ \\
\hline P2 & $23.5(20.6)$ & $35.4(40.6)$ & $59.6(42.2)$ & $0.029^{*}$ & $a^{*}$ \\
\hline P3 & $21.8(27.6)$ & $54.1(62.5)$ & $77.4(59.0)$ & $0.010^{\star \star}$ & $a^{\star \star}$ \\
\hline P4 & $15.5(8.5)$ & $37.7(36.9)$ & $88.4(38.1)$ & $0.000^{\star \star \star}$ & $a^{\star \star \star}, b^{\star \star \star}, c^{\star}$ \\
\hline P5 & $16.7(13.8)$ & $26.4(21.9)$ & $79.4(62.7)$ & $0.000^{\star \star \star}$ & $a^{\star \star \star}, b^{\star \star \star}$ \\
\hline AVG & $19.4(13.0)$ & $38.5(30.5)$ & $79.3(24.7)$ & $0.000^{\star \star \star}$ & $a^{\star \star \star}, b^{\star \star \star}, c^{\star}$ \\
\hline \multicolumn{6}{|c|}{ Vector to the start (degree) } \\
\hline P1 & $31.3(34.2)$ & $38.9(40.8)$ & $57.2(45.7)$ & 0.084 & \\
\hline P2 & $34.4(23.4)$ & $28.6(22.0)$ & $40.8(25.2)$ & 0.106 & \\
\hline P3 & $27.0(33.8)$ & $31.6(27.9)$ & $36.5(39.4)$ & 0.705 & \\
\hline P4 & $29.9(26.2)$ & 24.7 (20.9) & $52.5(49.1)$ & $0.023^{\star}$ & $b^{*}$ \\
\hline P5 & $34.1(28.3)$ & $45.1(39.6)$ & $71.9(46.0)$ & $0.021^{*}$ & $a^{*}$ \\
\hline AVG & $31.3(20.4)$ & $33.8(14.4)$ & $51.8(24.7)$ & $0.004^{\star \star}$ & $a^{\star \star}, b^{\star}$ \\
\hline
\end{tabular}

Data are presented as mean (standard deviation). Post hoc analysis by ANCOVA. $A D$, Alzheimer's disease; PrAD, prodromal $A D$; $C U$, cognitively unimpaired; a, $C U<A D$; b, $\operatorname{PrAD}<A D ; c, C U<\operatorname{PrAD} ; A V G$, average.

${ }^{\star} p \leq 0.05,{ }^{* *} p \leq 0.01,{ }^{* *} p \leq 0.001$.

statistical analysis. Baseline demographic characteristics, including age, education years, CASI scores, age at onset, and CDR scores, were coded as continuous variables. Other demographic characteristics, such as gender, were coded as category variables. One-way analysis of variance or Kruskal-Wallis test was used to analyze the demographic factors, and analysis of covariance was applied to analyze CASI, CERAD, time and distance perception, vector to the start, SoL, and the QuENA. Post hoc analysis, with the Bonferroni test, was used to compare the differences between each group. Pearson correlation analysis was used to check the correlations between the performance of the SoL and that of the QuENA. All the statistical tests were two-tailed, and significance levels were set at a $p$-value of $<0.05$.

\section{RESULTS}

\section{Basic Data}

A total of 77 subjects completed the study. Table 1 presents the demographic variables in the three groups: CU, PrAD, and AD subjects.

As shown in Table 1, the CASI and the CERAD scores revealed significant between-group differences. $\mathrm{AD}$ and $\mathrm{prAD}$ were more impaired in spatial navigation than $\mathrm{CU}$ as assessed by QuENA, while they showed no difference between each other. This finding was compatible with the hypothesis that the neural structures related to spatial navigation were damaged in the clinical stage of prAD. A chi-square analysis in GL percentage also revealed significant between-group distribution differences. It was also noted that education year differed with statistical significance between $\mathrm{CU}$ and $\mathrm{AD}$ people.

Regarding time perception, comparing prAD and $\mathrm{AD}$ patients with the CU group, verbal time estimation deviation and time production deviation showed significant differences (Table 2). $\mathrm{AD}$ produced more deviation in the test of distance production than prAD did; otherwise, no difference was detected among the groups in assessing perception of distance.

\section{Core Experiments}

As shown in Table 3, the SoL clearly differentiated among CU, prAD, and $\mathrm{AD}$. For example, the average linear deviation in 
meters in the $\mathrm{CU}$, prAD, and $\mathrm{AD}$ were $19 \pm 13,39 \pm 31$, and $79 \pm 25$, respectively ( $p<0.001$, post hoc comparisons $\mathrm{AD}$ vs. $\operatorname{prAD}: p<0.001 ; \mathrm{AD}$ vs. $\mathrm{CU}: p<0.001$; prAD vs. $\mathrm{CU}$ :

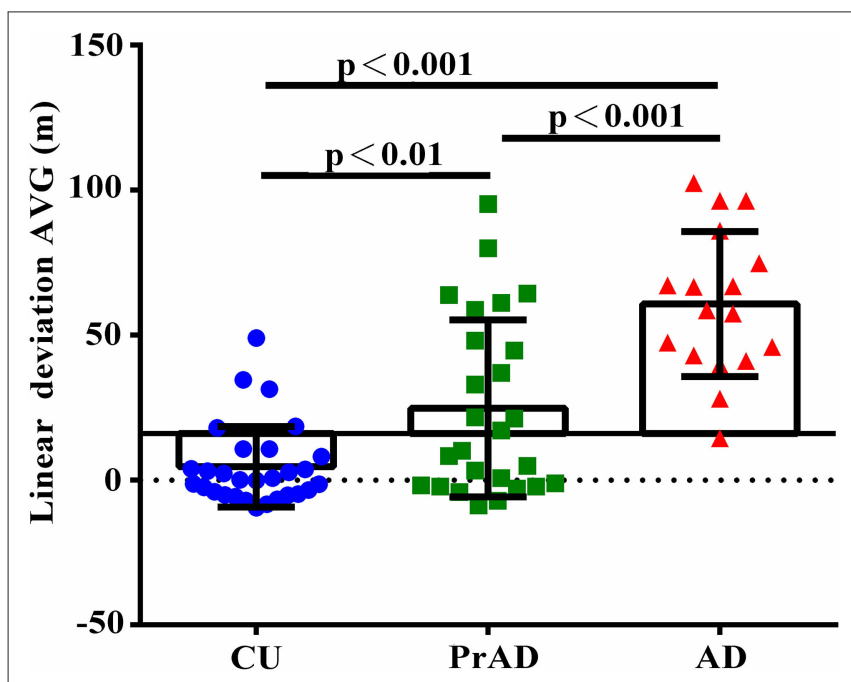

FIGURE 2 | The comparison of linear deviation among groups with post hoc comparison. $p<0.01$ ). Figure 2 illustrates the scattered plot of individual linear deviation together with the post hoc comparisons among $\mathrm{CU}$, prAD, and $\mathrm{AD}$. A difference was detected between $\mathrm{AD}$ and both prAD and $\mathrm{CU}$ in vector to the start in degrees, while no difference was noted between prAD and CU. Thus, the results showed that vector to the start might not serve as significant predictors for dementia status at the follow-up stage, particularly during the early stages of the disease.

Regarding linear deviation as a reference for diagnostic power, a deviation of $16 \mathrm{~m}$ was set as cutoff for comparison (Pai et al., 2016). The hit rates were $0.86,0.54$, and 0.05 for $C U$, prAD, and $\mathrm{AD}$, respectively ( $p<0.001$, post hoc comparisons $\mathrm{AD}$ vs. prAD, $p<0.001$; $\mathrm{AD}$ vs. $\mathrm{CU}, p<0.001$; $\operatorname{prAD}$ vs. $\mathrm{CU}, p<0.01$; Figure 3). The hit rates were well correlated with the presence of GL (correlation $=0.43$ with $p$-value $=0.001$ ).

The correlation between QuENA and linear deviation reached a statistical significance in average inattention for prAD patients as well as in average landmark scene agnosia and egocentric agnosia when considering all subjects (Table 4). Statistical significance was also attained in the correlation between the presence of GL and average landmark scene agnosia when prAD and $\mathrm{AD}$ subjects were considered (Table 5). When taking consideration of SoL and QuENA, a statistical significance was observed in several domains, including linear deviation

\section{Hit rates (16m) among groups (\%)}

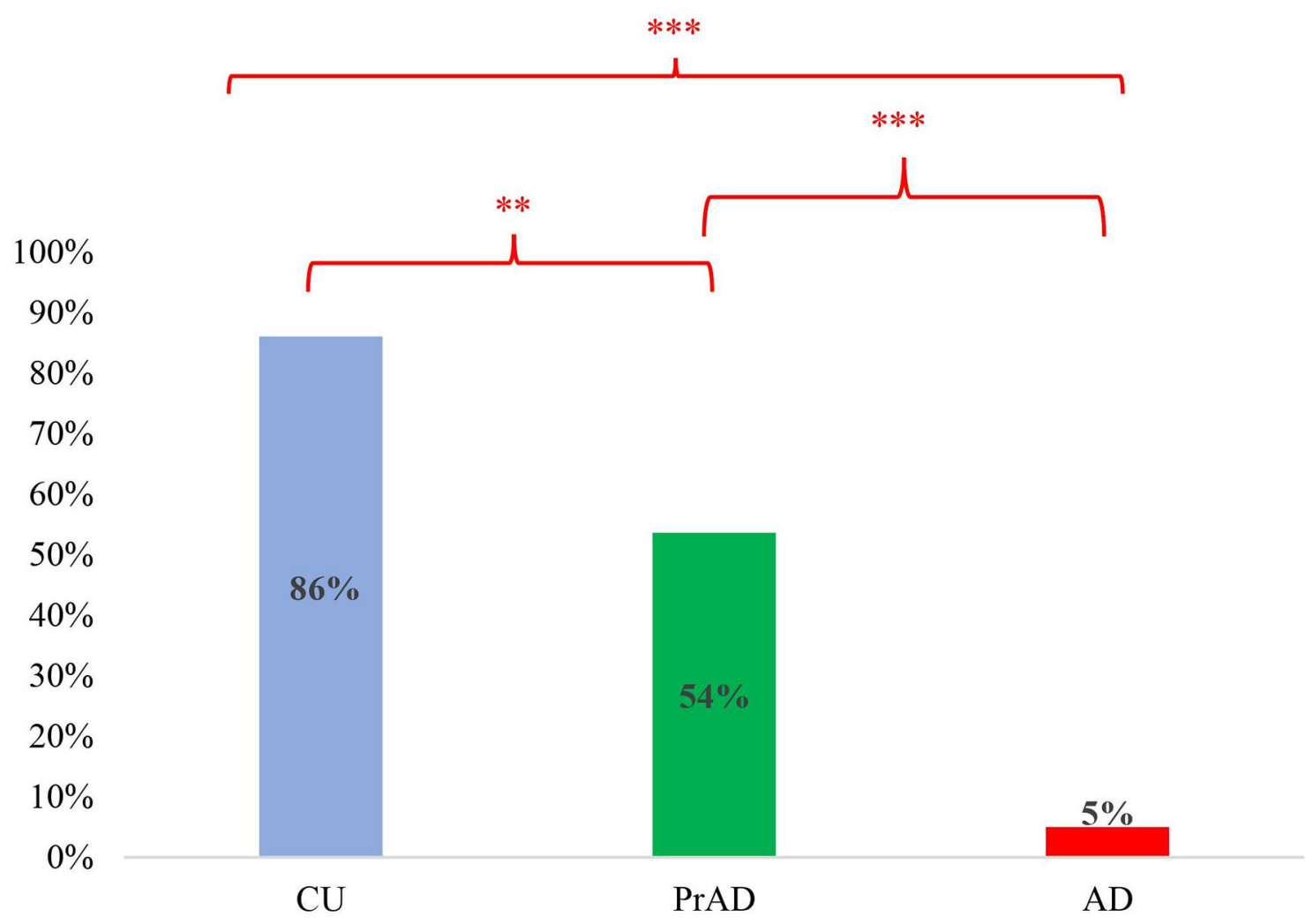

FIGURE 3 | The hit rates among groups with post hoc comparison $\left({ }^{* \star} p<0.01\right.$; $\left.{ }^{* *} p<0.001\right)$. 
TABLE 4 | Pearson correlation between QuENA and linear deviation.

\begin{tabular}{lccccc}
\hline & $\begin{array}{c}\text { Landmark } \\
\text { scene } \\
\text { agnosia }\end{array}$ & $\begin{array}{c}\text { Egocentric } \\
\text { agnosia }\end{array}$ & Inattention & $\begin{array}{c}\text { Heading } \\
\text { disorientation }\end{array}$ & Total score \\
\hline CU $(\boldsymbol{n}=\mathbf{2 9})$ & & & & \\
A & -0.009 & -0.083 & -0.103 & 0.079 & -0.027 \\
B & -0.039 & -0.147 & -0.162 & -0.196 & -0.154 \\
C & 0.181 & -0.278 & -0.096 & -0.106 & -0.053 \\
D & -0.108 & 0.052 & -0.107 & 0.243 & 0.014 \\
E & 0.153 & -0.249 & -0.137 & -0.082 & -0.060 \\
AVG & 0.079 & -0.253 & -0.187 & -0.053 & -0.096 \\
PrAD $(\boldsymbol{n}=27)^{\text {a }}$ & & & & & \\
A & -0.003 & -0.171 & -0.298 & -0.250 & -0.227 \\
B & -0.287 & $-0.394^{\star}$ & -0.357 & -0.111 & -0.334 \\
C & 0.100 & -0.216 & -0.335 & -0.099 & -0.108 \\
D & -0.201 & -0.343 & $-0.410^{*}$ & -0.161 & -0.267 \\
E & -0.285 & -0.228 & -0.115 & -0.004 & -0.124 \\
AVG & -0.125 & -0.360 & $-0.438^{\star}$ & -0.185 & -0.285 \\
AD $(\boldsymbol{n}=\mathbf{2 0})$ & & & & \\
A & -0.090 & -0.088 & 0.360 & 0.016 & 0.093 \\
B & 0.117 & 0.180 & -0.168 & -0.091 & -0.008 \\
C & -0.017 & 0.063 & 0.089 & -0.146 & -0.006 \\
D & -0.110 & 0.011 & -0.433 & -0.222 & -0.297 \\
E & -0.018 & -0.153 & -0.132 & 0.063 & -0.076 \\
AVG & -0.074 & -0.033 & -0.038 & -0.136 & -0.102 \\
Total $(\boldsymbol{n}=\mathbf{7 6})$ & & & & \\
A & 0.175 & 0.202 & 0.182 & 0.112 & 0.193 \\
B & 0.083 & 0.105 & -0.097 & 0.038 & 0.031 \\
C & $0.263^{\star}$ & 0.145 & 0.029 & 0.077 & 0.168 \\
D & 0.192 & $0.297^{\star \star}$ & -0.042 & 0.152 & 0.186 \\
E & 0.171 & 0.191 & 0.070 & 0.199 & 0.199 \\
AVG & $0.247^{\star}$ & $0.261^{*}$ & 0.055 & 0.158 & 0.221 \\
\hline a & & & & &
\end{tabular}

a Missing data in this value.

$C U$, cognitively unimpaired; $\operatorname{Pr} A D$, prodromal $A D ; A D$, Alzheimer's disease; AVG, average. ${ }^{*} p \leq 0.05,{ }^{* *} p \leq 0.01$.

with inattention for prAD subjects, and with landmark scene agnosia and with egocentric agnosia if all subjects were under consideration (Table 6).

\section{DISCUSSION}

Traditionally, the strategies a person may adopt for everyday navigation can be divided to egocentric and allocentric with adequate landmark recognition (Lester et al., 2017; Schoberl et al., 2020a). In this study, the SoL measured egocentric and allocentric strategies as well as the translation between these two spatial representations (Pai and Yang, 2013), matching and judging the current location with reference to cognitive maps, and prefrontal functions (Jeffery, 2007). Hence, SoL reflected a more holistic approach to real-world navigation, and impairment of it may contribute to the occurrence of GL (Yatawara et al., 2017) and result in the inability to lead an independent life. Conceptually, SoL is analogous to the function of grid cells (Howett et al.,
2019), and that the entorhinal cortex underpins navigation in other mammalian species is supported by the demonstration of entorhinal cortex grid cells in rats (Hafting et al., 2005), bats (Yartsev et al., 2011), monkeys (Killian and Buffalo, 2018), and humans (Jacobs et al., 2013). Since the entorhinal cortex and its connections are highly related to early pathological changes in $\mathrm{AD}$ patients, a device designed based on grid-cell function might be a good way to depict the ways in which how SNI troubles community-residing people with AD (Pai and Jacobs, 2004).

This study demonstrated that SoL, as assessed by linear deviation by a grid-cell function driven device, was more impaired in $\mathrm{AD}$ and PrAD than in $\mathrm{CU}$. This distinct feature among the three groups was further supported by the hit rates of $16 \mathrm{~m}$ in terms of positioning precision (Figure 3). How one senses the current location in a specific surrounding is an interesting topic for neuroscientists. SoL helps navigators to judge one's present location relative to the start point or to the destination. As mentioned, to know if an individual has reached a pre-set destination in an environment, the individual may have to use multiple mental resources, including path integration, cognitive maps, landmark recognition, and translation of different spatial representations (Jheng and Pai, 2009; Lee and Pai, 2012; Pai and Yang, 2013). When applying this scenario to a person with PrAD or mild $\mathrm{AD}$ in a real-world situation who is ambulating on a daily route, it is reasonable to postulate that an impaired SoL may emerge intermittently long before the occurrence of his or her first-ever GL event because the individual may have impairment in one or more of the mentioned mental resources (Tu and Pai, 2006).

The performance of SoL observed in prAD in this study was in accordance with previous human navigation research (Howett et al., 2019). Although detailed history could not be obtained from these patients because of their impaired episodic memory, from clinical observation, many of them had spent extra time trying to recover the ability. In the current study, the neural substrates accountable for SoL function in both prAD and $\mathrm{AD}$ were supposedly damaged (Braak and Del Tredici, 2015), and the deficits of the SoL function shown in this study, both prAD and $\mathrm{AD}$ being worse than $\mathrm{CU}$, supported this hypothesis.

From the concept of dead reckoning, the perception of time, distance or speed, and direction is critical for ocean sailors to reach a destination where no landmarks such as islets are present between the start point and the destination. In this study, we assessed perception of time and distance because the SoL depended on these basic abilities, and we tried to eliminate these confounders. Unexpectedly, the results revealed differences in several situations among the groups. How these differences would affect the SoL needs future well-designed research to answer.

The relationships among SoL, spatial navigation, and cognitive functions deserve further discussion. Except for moderate cognitive decline as in the clinical stage of mild and more advanced dementia, the cognitive functions and daily navigation abilities are not parallel. As mentioned, the cerebral cortical areas responsible for spatial navigation were supposedly damaged in prAD and mild $\mathrm{AD}$, while a trend was present for a lower rate of $\mathrm{GL}$ in prAD to $\mathrm{AD}$, though not reaching 
TABLE 5 | Pearson correlation between GL and QuENA and between GL and SoL.

\begin{tabular}{|c|c|c|c|c|c|c|c|}
\hline & \multicolumn{5}{|c|}{ QuENA } & \multicolumn{2}{|c|}{ Sense of location } \\
\hline & Landmark scene agnosia & Egocentric agnosia & Inattention & Heading disorientation & Total score & Liner deviation & $\begin{array}{l}\text { Vector to } \\
\text { the start }\end{array}$ \\
\hline $\operatorname{PrAD}(n=28)$ & -0.247 & -0.256 & -0.024 & -0.246 & -0.117 & -0.29 & -0.00 \\
\hline $\operatorname{AD}(n=20)$ & -0.431 & -0.049 & -0.176 & -0.067 & -0.285 & 0.04 & 0.11 \\
\hline $\operatorname{PrAD}+\operatorname{AD}(n=48)$ & $-0.348^{\star}$ & -0.211 & -0.112 & -0.184 & -0.210 & -0.23 & -0.03 \\
\hline
\end{tabular}

PrAD, prodromal $A D ; A D$, Alzheimer's disease.

${ }^{*} p \leq 0.05$.

TABLE 6 | Pearson correlation between sense of location and QUENA.

\begin{tabular}{|c|c|c|c|c|c|}
\hline & Landmark scene agnosia & Egocentric agnosia & Inattention & Heading disorientation & Total score \\
\hline \multicolumn{6}{|l|}{$\mathrm{CU}(n=29)$} \\
\hline Linear deviation & 0.079 & -0.253 & -0.187 & -0.053 & -0.096 \\
\hline Vector to the start & -0.003 & -0.171 & -0.023 & 0.035 & -0.042 \\
\hline \multicolumn{6}{|l|}{$\operatorname{PrAD}(n=28)$} \\
\hline Linear deviation & -0.125 & -0.360 & $-0.438^{\star}$ & -0.185 & -0.285 \\
\hline Vector to the start & -0.139 & -0.196 & -0.174 & 0.005 & -0.040 \\
\hline \multicolumn{6}{|l|}{$\mathrm{AD}(n=20)$} \\
\hline Linear deviation & -0.074 & -0.033 & -0.038 & -0.136 & -0.102 \\
\hline Vector to the start & -0.077 & -0.134 & -0.034 & -0.435 & -0.233 \\
\hline \multicolumn{6}{|c|}{$\operatorname{PrAD}+\operatorname{AD}(n=48)$} \\
\hline Linear deviation & -0.019 & -0.021 & -0.171 & -0.084 & -0.067 \\
\hline Vector to the start & -0.045 & -0.021 & -0.049 & -0.160 & -0.036 \\
\hline \multicolumn{6}{|l|}{ Total $(n=77)$} \\
\hline Linear deviation & $0.247^{\star}$ & $0.261^{\star}$ & 0.055 & 0.158 & 0.221 \\
\hline Vector to the start & 0.086 & 0.080 & 0.049 & 0.005 & 0.085 \\
\hline
\end{tabular}

$C U$, cognitively unimpaired; $\operatorname{Pr} A D$, prodromal $A D ; A D$, Alzheimer's disease.

${ }^{*} p \leq 0.05$.

statistical significance. One reason was that factors unrelated to spatial cognition might prevent individuals with cognitive impairment from GL. For example, in their daily lives, people with prAD may preserve an adequate problem-solving ability and adopt compensatory strategies, such as using cues or indices as they are encountered with an impaired SoL. They may also call family members, ask others nearby or police officers for guidance, or take a taxi home. In this study, that the prAD had better performance on many items in CASI and in CERAD supports this hypothesis. Theoretically speaking, the parietal lobe as an integration center for multi-modality sensory information for successful navigation is functioning much better in prAD than in mild AD (Jeffery, 2007; Braak and Del Tredici, 2015). This is another explanation for the lower GL rate in prAD. On the other hand, that an impaired SoL in people at risk can be compensated for by proper means to prevent GL is insightful for comprehensive dementia care since a certain proportion of older adults suffer from cognitive impairment and are in danger of an unexpected GL event. In this study, that the $\mathrm{AD}$ and prAD groups manifested worse SoL and daily navigation abilities than the CU was compatible with the trend of the Alzheimer continuum in cognitive decline (Table 2). However, this finding was not in line with the daily navigation abilities in that the QuENA showed no difference between prAD and AD. From our previous study, the QuENA, as assessed by the caregivers or family members, did not faithfully reflect the awareness of the targeted persons with $\mathrm{AD}$ (Pai and Lee, 2016). The QuENA reported by prAD, as in this study, was usually underestimated in part due to preserved insight and anxiety and might lead to a discrepancy between the QuENA and the performance of SoL.

Regarding the vector to the start as a function of path integration, $\mathrm{AD}$ was worse than both prAD and $\mathrm{CU}$, but no difference was detected between prAD and CU. Given that prAD's brain substrate responsible for path integration was damaged, however, the results did not support this hypothesis. In fact, the location of the neural substrates responsible for path integration in humans is controversial (Dudchenko, 2010). The path integration paradigm used in this study might be too simple, or other neural substrates may play a role in path integration as well. From these findings, it is suggested that SoL is better than path integration in differentiating $\mathrm{CU}$, prAD, and mild AD. 
Recently, papers focusing on spatial navigation as a marker to detect preclinical $\mathrm{AD}$ or to predict the conversion from MCI to AD have provided insightful information (Howett et al., 2019; Levine et al., 2020; Schoberl et al., 2020b). Our current results added further support for this possibility. Since the entorhinal cortex which contain lots of grid cells plays a sentinel role for signaling $\mathrm{AD}$, how to crystalize the concept of grid-cell-related functions and create devices to differentiate prAD from other subtypes of MCI is mandatory (Moodley et al., 2015; Allison et al., 2016; Coughlan et al., 2018; Ritchie et al., 2018). These devices may also increase the confidence of physicians to make diagnoses of prAD and provide both patients and caregivers with information about the future progression. From our study, the presence of impaired SoL was linked to a danger of GL; hence, the caregivers can take action in advance to prevent the events.

Limitations included the relatively small number of $\mathrm{AD}$ participants. The design of the experiments in this study was complicated, which prevented more advanced $\mathrm{AD}$ patients from completing the procedures. Only cases with very mild or mild AD were feasible to join and complete the study. Another limitation concerns the lack of biomarkers, such as cerebrospinal fluid or amyloid positron emission tomography, to support a diagnosis of prAD or AD. However, this is a real-world difficulty; cheaper and more reliable biomarkers are needed to conquer this limitation.

Collectively, this work contributed to the growing body of evidence that impaired SoL appeared in the early clinical stage of $\mathrm{AD}$ and was associated with daily navigation impairment (Monacelli et al., 2003; Pai and Jacobs, 2004). Without efficient problem-solving strategies or help from pedestrians, an escort to the police station is inevitable; indeed a tragedy may even occur. Persistent and longitudinal studies of SoL in these participants are mandatory before its clinical application as a useful behavioral maker for $\mathrm{AD}$.

\section{REFERENCES}

Allan, L. G. (1979). The perception of time. Percept. Psychophys. 26, 340-354. doi: 10.3758/BF03204158

Allison, S. L., Fagan, A. M., Morris, J. C., and Head, D. (2016). Spatial navigation in preclinical Alzheimer's Disease. J. Alzheimers Dis. 52, 77-90. doi: 10.3233/JAD-150855

Baddeley, A. D. (1986). Working Memory. Oxford: Oxford University Press.

Bian, Z., and Anderson, G. J. (2013). Aging and the perception of egocentric distance. Psychol. Aging 28, 813-825. doi: 10.1037/a00 30991

Bindra, D., and Waksberg, H. (1956). Methods and terminology in studies of time estimation. Psychol. Bull. 53, 155-159. doi: 10.1037/h00 41810

Braak, H., and Del Tredici, K. (2015). The preclinical phase of the pathological process underlying sporadic Alzheimer's disease. Brain 138, 2814-2833. doi: 10.1093/brain/awv236

Busse, A., Bischkopf, J., Riedel-Heller, S. G., and Angermeyer, M. C. (2003). Mild cognitive impairment: prevalence and incidence according to different diagnostic criteria. results of the leipzig longitudinal study of the aged (LEILA75+). Br. J. Psychiatry 182, 449-454. doi: 10.1192/bjp.182.5.449

Coughlan, G., Laczo, J., Hort, J., Minihane, A. M., and Hornberger, M. (2018). Spatial navigation deficits - overlooked cognitive marker for preclinical Alzheimer disease? Nat. Rev. Neurol. 14, 496-506. doi: 10.1038/s41582-018-0031-x

\section{DATA AVAILABILITY STATEMENT}

The raw data supporting the conclusions of this article will be made available by the authors, without undue reservation.

\section{ETHICS STATEMENT}

The studies involving human participants were reviewed and approved by National Cheng Kung University Hospital Institutional Review Board for the Protection of Human Subjects. The patients/participants provided their written informed consent to participate in this study.

\section{AUTHOR CONTRIBUTIONS}

M-CP undertook the literature search, study design, device design, conduct of data analysis, and editing of the author contributions and was mainly responsible for the revisions and drafts of the manuscript. S-SJ participated in the device design and data analysis and contributed to the revisions and the final draft of the manuscript. Both authors contributed to the article and approved the submitted version.

\section{FUNDING}

This study was sponsored by grants MOST 106-2627-M-006-007 and MOST 108-2321-B-006-003 to M-CP.

\section{ACKNOWLEDGMENTS}

Part of this study has been reported as poster at AAIC 2018, held in Chicago, IL, USA.

Dudchenko, P. A. (2010). “The neural basis for a sense of direction: head direction neurons," in Why People Get Lost? The Psychology and Neuroscience of Spatial Cognition, ed P. A. Dudchenko (New York, NY: Oxford University Press), 191.

Gazova, I., Vlcek, K., Laczo, J., Nedelska, Z., Hyncicova, E., Mokrisova, I., et al. (2012). Spatial navigation-a unique window into physiological and pathological aging. Front. Aging Neurosci. 4, 1-19. doi: 10.3389/fnagi.2012.00016

Golob, E. J., Stackman, R. W., Wong, A. C., and Taube, J. S. (2001). On the behavioral significance of head direction cells: neural and behavioral dynamics during spatial memory tasks. Behav. Neurosci. 115, 285-304. doi: 10.1037/0735-7044.115.2.285

Grondin, S. (2010). Timing and time perception: a review of recent behavioral and neuroscience findings and theoretical directions. Atten. Percep. Psychophys. 72, 561-582. doi: 10.3758/APP.72.3.561

Hafting, T., Fyhn, M., Molden, S., Moser, M. B., and Moser, E. I. (2005) Microstructure of a spatial map in the entorhinal cortex. Nature 436, 801-806. doi: 10.1038/nature03721

Hort, J., Laczo, J., Vyhnalek, M., Bojar, M., Bures, J., and Vlcek, K. (2007). Spatial navigation deficit in amnestic mild cognitive impairment. Proc. Natl. Acad. Sci. U. S. A. 104, 4042-4047. doi: 10.1073/pnas.0611314104

Howett, D., Castegnaro, A., Krzywicka, K., Hagman, J., Marchment, D., Henson, et al. (2019). Differentiation of mild cognitive impairment using an entorhinal cortex-based test of virtual reality navigation. Brain 142, 1751-1766. doi: 10.1093/brain/awz116

Jacobs, J., Weidemann, C. T., Miller, J. F., Solway, A., Burke, J. F., Wei, X., et al. (2013). Direct recordings of grid-like neuronal activity in 
human spatial navigation. Nat. Neurosci. 6, 1188-1190. doi: 10.1038/ nn.3466

Janzen, G., and van Turennout, M. (2004). Selective neural representation of objects relevant for navigation. Nat. Neurosci. 7, 673-677. doi: 10.1038/nn1257

Jeffery, K. J. (2007). Self-localization and the entorhinal-hippocampal system. Curr. Opin. Neurobiol. 17, 684-691. doi: 10.1016/j.conb.2007.11.008

Jheng, S. S., and Pai, M. C. (2009). Cognitive map in patients with mild Alzheimer's disease: a computer-generated arena study. Behav. Brain. Res. 200, 42-47. doi: 10.1016/j.bbr.2008.12.029

Killian, N. J., and Buffalo, E. A. (2018). Grid cells map the visual world. Nat. Neurosci. 21, 161-162. doi: 10.1038/s41593-017-0062-4

Lee, Y. T., and Pai, M. C. (2012). Recognition of personally familiar scenes in patients with very mild Alzheimer's disease: effects of spatial frequency and luminance. J. Alzheimers Dis. 29, 441-448. doi: 10.3233/JAD-2011-111601

Lester, A. W., Moffat, S. D., Wiener, J. M., Barnes, C. A., and Wolbers, T. (2017). The aging navigational system. Neuron 95, 1019-1035. doi: 10.1016/j.neuron.2017.06.037

Levine, T. F., Allison, S. L., Stojanovic, M., Fagan, A. M., Morris, J. C., and Head, D. (2020). Spatial navigation predicts progression of dementia symptomatology. Alzheimers Dement. 16, 491-500. doi: 10.1002/alz.12031

Lithfous, S., Dufour, A., and Despres, O. (2013). Spatial navigation in normal aging and the prodromal stage of Alzheimer's disease: insights from imaging and behavioral studies. Ageing Res. Rev. 12, 201-213. doi: 10.1016/j.arr.2012.04.007

Matsuda, H. (2007). Role of neuroimaging in Alzheimer's disease, with emphasis on brain perfusion SPECT. J. Nucl. Med. 48, 1289-1300. doi: 10.2967/jnumed.106.037218

McKhann, G. M., Knopman, D. S., Chertkow, H., Hyman, B. T., Jack, C. R. Jr., Kawas, C. H., et al. (2011). The diagnosis of dementia due to Alzheimer's disease: recommendations from the National Institute on Aging-Alzheimer's Association workgroups on diagnostic guidelines for Alzheimer's disease. Alzheimers Dement. 7, 263-269. doi: 10.1016/j.jalz.2011.03.005

Monacelli, A. M., Cushman, L. A., Kavcic, V., and Duffy, C. J. (2003). Spatial disorientation in Alzheimer's disease: the remembrance of things passed. Neurology 61, 1491-1497. doi: 10.1212/WNL.61.11.1491

Moodley, K., Minati, L., Contarino, V., Prioni, S., Wood, R., Cooper, R., et al. (2015). Diagnostic differentiation of mild cognitive impairment due to Alzheimer's disease using a hippocampus-dependent test of spatial memory. Hippocampus 25, 939-951. doi: 10.1002/hipo.22417

Morris, J. C., Heyman, A., Mohs, R. C., Hughes, J. P., van Belle, G., Fillenbaum, G., et al. (1989). The Consortium to establish a registry for Alzheimer's Disease (CERAD). Part I. Clinical and neuropsychological assessment of Alzheimer's disease. Neurology 39, 1159-1165. doi: 10.1212/WNL.39.9.1159

Pai, M. C., and Hsiao, S. (2002). Incipient symptoms of Alzheimer's disease and effect of education on the onset age: a study of 155 Taiwanese patients. Acta Neurol. Taiwan 11, 66-69.

Pai, M. C., and Jacobs, W. J. (2004). Topographical disorientation in communityresiding patients with Alzheimer's disease. Int. J. Geriatr. Psychiatry 19, 250-255. doi: 10.1002/gps.1081

Pai, M. C., and Lee, C. C. (2016). The incidence and recurrence of getting lost event in community-dwelling patients with Alzheimer's disease: a 2.5-year follow-up. PLoS ONE 11:e0155480. doi: 10.1371/journal.pone.0155480

Pai, M. C., Lee, C. C., Yang, Y. C., Lee, Y. T., Chen, K. C., Lin, S. H., et al. (2012). Development of a questionnaire on everyday navigational ability to assess topographical disorientation in Alzheimer's Disease. Am. J. Alzheimers Dis. Other Demen. 27, 65-72. doi: 10.1177/1533317512436805

Pai, M. C., Tsao, S. H., and Jan, S. S. (2016). Sense of location in people with Alzheimer's disease. Gerontechnology 15:114s. doi: 10.1016/j.jalz.2016.06.1567

Pai, M. C., and Yang, Y. C. (2013). Impaired translation of spatial representation in young onset Alzheimer's disease patients. Curr. Alzheimer Res. 10, 95-103. doi: 10.2174/1567205011310010013

Parron, C., and Save, E. (2004). Evidence for entorhinal and parietal cortices involvement in path integration in the rat. Exp. Brain Res. 159, 349-359. doi: 10.1007/s00221-004-1960-8
Petersen, R. C. (2004). Mild cognitive impairment as a diagnostic entity. J. Intern. Med. 256, 183-194. doi: 10.1111/j.1365-2796.2004.01388.x

Petersen, R. C., Smith, G. E., Waring, S. C., Ivnik, R. J., Tangalos, E. G., and Kokmen, E. (1999). Mild cognitive impairment: clinical characterization and outcome. Arch. Neurol. 56, 303-308. doi: 10.1001/archneur.56.3.303

Ramusino, M. C., Altomare, D., Bacchin, R., Ingala, S., Bna, C., and Bonetti, M. (2019). Medial temporal lobe atrophy and posterior atrophy scales normative values. NeuroImage Clin. 24:101936. doi: 10.1016/j.nicl.2019.101936

Ritchie, K., Carrière, I., Howett, D., Su, L., Hornberger, M., O’Brien, J. T., et al. (2018). Allocentric and egocentric spatial processing in middle-aged adults at high risk of late-onset Alzheimer's Disease: The PREVENT Dementia Study. J. Alzheimers Dis. 65, 885-896. doi: 10.3233/JAD-180432

Scheltens, P., Leys, D., Barkhof, F., Huglo, D., Weinstein, H. C., Vermersch, P., et al. (1992). Atrophy of medial temporal lobes on MRI in 'probable' Alzheimer's disease and normal ageing: diagnostic value and neuropsychological correlates. J. Neurol. Neurosurg. Psychiatry 55, 967-972. doi: 10.1136/jnnp.55.10.967

Schoberl, F., Pradhan, C., Irving, S., Buerger, K., Xiong, G., Kugler, G., et al. (2020a). Real-space navigation testing differentiates between amyloid-positive and -negative aMCI. Neurology 94, e861-e873. doi: 10.1212/WNL.0000000000008758

Schoberl, F., Zwergal, A., and Brandt, T. (2020b). Testing navigation in teal space: contributions to understanding the physiology and pathology of human navigation control. Front. Neural. Circuits 14:6. doi: 10.3389/fncir.2020.00006

Suk, H. I., and Shen, D. (2014), Clustering-induced multi-task learning for AD/MCI classification. Med. Image Comput. Comput. Assist. Interv. 17, 393-400. doi: 10.1007/978-3-319-10443-0_50

Teng, E. L., Hasegawa, K., Homma, A., Imai, Y., Larson, E., Graves, A., et al. (1994). The Cognitive Abilities Screening Instrument (CASI): a practical test for cross-cultural epidemiological studies of dementia. Int. Psychogeriatr. 6, 45-58. doi: 10.1017/S1041610294001602

Tu, M. C., and Pai, M. C. (2006). Getting lost for the first time in patients with Alzheimer's disease. Int. Psychogeriatr. 18, 567-570. doi: 10.1017/S1041610206224025

Vann, A. D., Aggleton, J. P., and Maguire, M. A. (2009). What does the retrosplenial cortex do? Nat. Rev. Neurosci. 10, 792-802. doi: 10.1038/nrn2733

Vogeley, K., and Flink, G. R. (2003). Neural correlates of the fist-personperspective. Trends Cogn. Sci. 7, 38-42. doi: 10.1016/S1364-6613(02)00003-7

Winblad, B., Palmer, K., Kivipelto, M., Jelic, V., Fratiglioni, L., Wahlund, L. O., et al. (2004). Mild cognitive impairment-beyond controversies, towards a consensus: report of the international working group on mild cognitive impairment. J. Intern. Med. 256, 240-246. doi: 10.1111/j.1365-2796.2004.01380.x

Yartsev, M. M., Witter, M. P., and Ulanovsky, N. (2011). Grid cells without theta oscillations in the entorhinal cortex of bats. Nature 479, 103-107. doi: 10.1038/nature10583

Yatawara, C., Lee, D. R., Lim, L., Zhou, J., and Nagaendran, K. (2017). Getting lost behavior in patients with very mild Alzheimer's disease: a cognitive and anatomical model. Front. Med. 4:201. doi: 10.3389/fmed.2017.00201

Zanco, M., Plácido, J., Marinho, V., Ferreira, J. V., de Oliveira, F., MonteiroJunior, R., et al. (2018). Spatial navigation in the elderly with Alzheimer's Disease: a cross-sectional study. J. Alzheimers Dis. 66, 1683-1694. doi: 10.3233/JAD-180819

Conflict of Interest: The authors declare that the research was conducted in the absence of any commercial or financial relationships that could be construed as a potential conflict of interest.

Copyright (c) 2020 Pai and Jan. This is an open-access article distributed under the terms of the Creative Commons Attribution License (CC BY). The use, distribution or reproduction in other forums is permitted, provided the original author(s) and the copyright owner(s) are credited and that the original publication in this journal is cited, in accordance with accepted academic practice. No use, distribution or reproduction is permitted which does not comply with these terms. 